Pesq. Vet. Bras. 38(4):665-669, abril 2018

\title{
Prevalência de Mycoplasma bovis em rebanhos de vacas leiteiras ${ }^{1}$
}

\author{
Marcela P. Manzi², Sâmea F. Joaquim², Felipe F. Guimarães², \\ Ariane Cristina M.O. Bruder-Nascimento ${ }^{2}$, José Carlos F. Pantoja ${ }^{2}$ e Helio Langoni ${ }^{2 *}$
}

\begin{abstract}
Manzi M.P., Joaquim S.F., Guimarães F.F., Bruder-Nascimento A.C.M.O., Pantoja J.C.F. \& Langoni H. 2018. [Prevalence of Mycoplasma bovis in dairy herds]. Prevalência de Mycoplasma bovis em rebanhos de vacas leiteiras. Pesquisa Veterinária Brasileira 38(4):665-669. Departamento de Higiene Veterinária e Saúde Pública, Faculdade de Medicina Veterinária e Zootecnia, Universidade Estadual Paulista “Julio de Mesquita Filho", Distrito de Rubião Júnior, Botucatu, SP 18618-970, Brazil. E-mail: hlangoni@fmvz.unesp.br

Mycoplasma is a highly contagious pathogen, which can cause mastitis, pneumonia, arthritis, among other diseases. Its isolation requires specific means and conditions due to its fastidious growth. Due to the complexity of its diagnosis, it is believed that the real prevalence of mastitis cases by Mycoplasma is underestimated. The objective of the present study was to identify the prevalence of Mycoplasma bovis in different dairy herds in the state of São Paulo. The study was divided into a screening phase in which samples were collected from 67 expansion tanks and individual collection, in which positive properties for $M$. bovis were visited and collected milk samples from all animals with clinical and subclinical mastitis. The laboratory diagnosis was made through PCR and specific microbiological culture. The prevalence of $M$. bovis found in the screening phase was $1.4 \%$. In the individual phase, all milk samples from $M$. bovis positive property in the expansion tank were negative, which allows to conclude the low prevalence of the agent under the conditions of the present study.
\end{abstract}

INDEX TERMS: Mycoplasma bovis, dairy herd, mastitis, milk quality, cattle, bacterioses.

RESUMO.- Mycoplasma é um patógeno altamente contagioso, podendo causar mastite, pneumonia, artrite, entre outras enfermidades. Seu isolamento requer meios e condições específicas devido ao seu crescimento fastidioso. Devido à complexidade do seu diagnóstico, acredita-se que a real prevalência de casos de mastite por micoplasma seja subestimada. 0 objetivo do presente estudo foi identificar a prevalência de Mycoplasma bovis em diferentes rebanhos de bovinos leiteiros no estado de São Paulo. 0 estudo foi dividido em fase de triagem, na qual colheram-se amostras de 67 tanques de expansão e a coleta individual, na qual propriedades positivas para $M$. bovis foram visitadas e colhidas amostras de leite de todos os animais com mastite clínica e subclínica. 0 diagnóstico laboratorial foi feito por meio da PCR

\footnotetext{
${ }^{1}$ Recebido em 20 de abril de 2017.

Aceito para publicação em 22 de maio de 2017.

${ }^{2}$ Departamento de Higiene Veterinária e Saúde Pública, Faculdade de Medicina Veterinária e Zootecnia, Universidade Estadual Paulista “Julio de Mesquita Filho" (Unesp), Distrito de Rubião Júnior, Botucatu, SP 18618-970, Brasil. E-mails: marcela.pmanzi@gmail.com, sameajoaquim@gmail.com, felipefreitasguimaraes@hotmail.com, arianeoli@yahoo.com.br,pantoja@fmvz.unesp. br; *Autor para correspondência: hlangoni@fmvz.unesp.br
}

e cultivo microbiológico específico. A prevalência de $M$. bovis encontrada na fase de triagem foi de $1,4 \%$. Na fase individual, todas as amostras de leite, procedentes de propriedade positiva para M. bovis no tanque de expansão, foram negativas, o que permite concluir pela baixa prevalência do agente nas condições do presente estudo.

TERMOS DE INDEXAÇÃO: Mycoplasma bovis, rebanho, vacas leiteiras, mastite, qualidade do leite, bovinos, bacterioses.

\section{INTRODUÇÃO}

Mycoplasma spp. são as menores células procariontes capazes de autorreplicação. Não possuem parede celular rígida, apresentando membranas externas flexíveis com três extratos, susceptíveis à dessecação, calor, detergentes e aos desinfetantes (Quinn et al. 2005) e resistentes aos principais antimicrobianos disponíveis (Owens \& Nipper 2008).

É um patógeno altamente contagioso, podendo causar mastites, pneumonias, artrite, otite e menos frequentemente abortamentos e meningites (Nicholas \& Ayling 2003). As duas espécies de micoplamas mais comuns nas mastites bovinas 
são Mycoplasma bovis e Mycoplasma californicum, sendo a primeira considerada como principal espécie em surtos de mastites, em diversas partes do mundo (Nicholas et al. 2008).

0 isolamento de micoplasma requer meios de cultura e tempo de incubação especiais, além de condições de microaerofilia, fato que muitas vezes pode redundar em culturas de amostras de leite de casos de mastite, apresentarem-se negativas a partir de métodos microbiológicos padrões (Langoni 2013). $\mathrm{O}$ isolamento de micoplasmas pode ser prejudicado também mesmo quando se utilizam condições ideais, pois o tipo de amostra clínica, o método de coleta e o transporte, a exigência nutricional e o número de micoplasmas viáveis na amostra podem interferir no resultado (Buzinhani et al. 2007).

Pelo fato do Mycoplasma bovis necessitar de métodos complexos para o seu isolamento e identificação, acredita-se que a sua real prevalência seja, provavelmente, subestimada (Kampa et al. 2009), sendo casos de mastites causadas por Mycoplasma sub diagnosticados (Fox et al. 2005).

De acordo com a literatura, verifica-se prevalência de 0,5 a 35\% de mastite causadas por Mycoplasma bovis em diversos países (González \& Wilson 2003). No Brasil, a pesquisa desse agente, assim como de outras espécies de micoplasmas, tanto nas mastites como em outras patologias dos sistemas respiratório, urogenital, articulações, sistema nervoso e conjuntiva ocular são pouco frequentes (Buzinhani et al. 2007), considerando-se as dificuldades já assinaladas.

No Brasil, os únicos estudos sobre o assunto estão restritos a surtos nos estados do Paraná (Mettifogo et al. 1996) e Minas
Gerais (Mettifogo \& Tamaso 2013), além de um estudo de Pretto et al. (2001) também no Paraná e outro em São Paulo, relatando baixa prevalência de Mycoplasma bovis (1,12\%). Dessa maneira, estudos da prevalência de micoplasmas e os reflexos desse agente como causador de mastites são necessários, visando subsidiar pesquisadores, orientar os produtores, informar órgãos competentes na fiscalização da qualidade do leite e consultores.

Atualmente, as principais medidas de controle das mastites por M. bovis são a detecção e segregação de animais infectados, seguido do descarte. Para isso, é necessário conhecer a real prevalência do agente nos rebanhos, delineando assim medidas estratégicas eficazes.

\section{MATERIAL E MÉTODOS}

Foram utilizadas no estudo amostras de leite bovino de diferentes rebanhos localizados no interior do estado de São Paulo, nos seguintes municípios: Botucatu, Bofete, Porangaba, Itatinga, São Pedro e Piracicaba (Fig.1). Dispostos na região central do estado, estes municípios apresentam altitudes entre 525 e $845 \mathrm{~m}$, clima predominantemente subtropical úmido (Botucatu, Bofete e Porangaba) e tropical (Piracicaba, São Pedro e Itatinga).

Para determinação do $n$ amostral necessário para realização do estudo, utilizou-se prevalência estimada de 5\% de Mycoplasma bovis no leite, com base em outros estudos (Fox et al. 2005), com intervalo de confiança de $95 \%$ e margem de erro de $5 \%$, baseado em uma população estimada de 800 rebanhos, existentes no estado de São Paulo, obtendo-se um número de 67 propriedades.

\section{Área de Estudo}
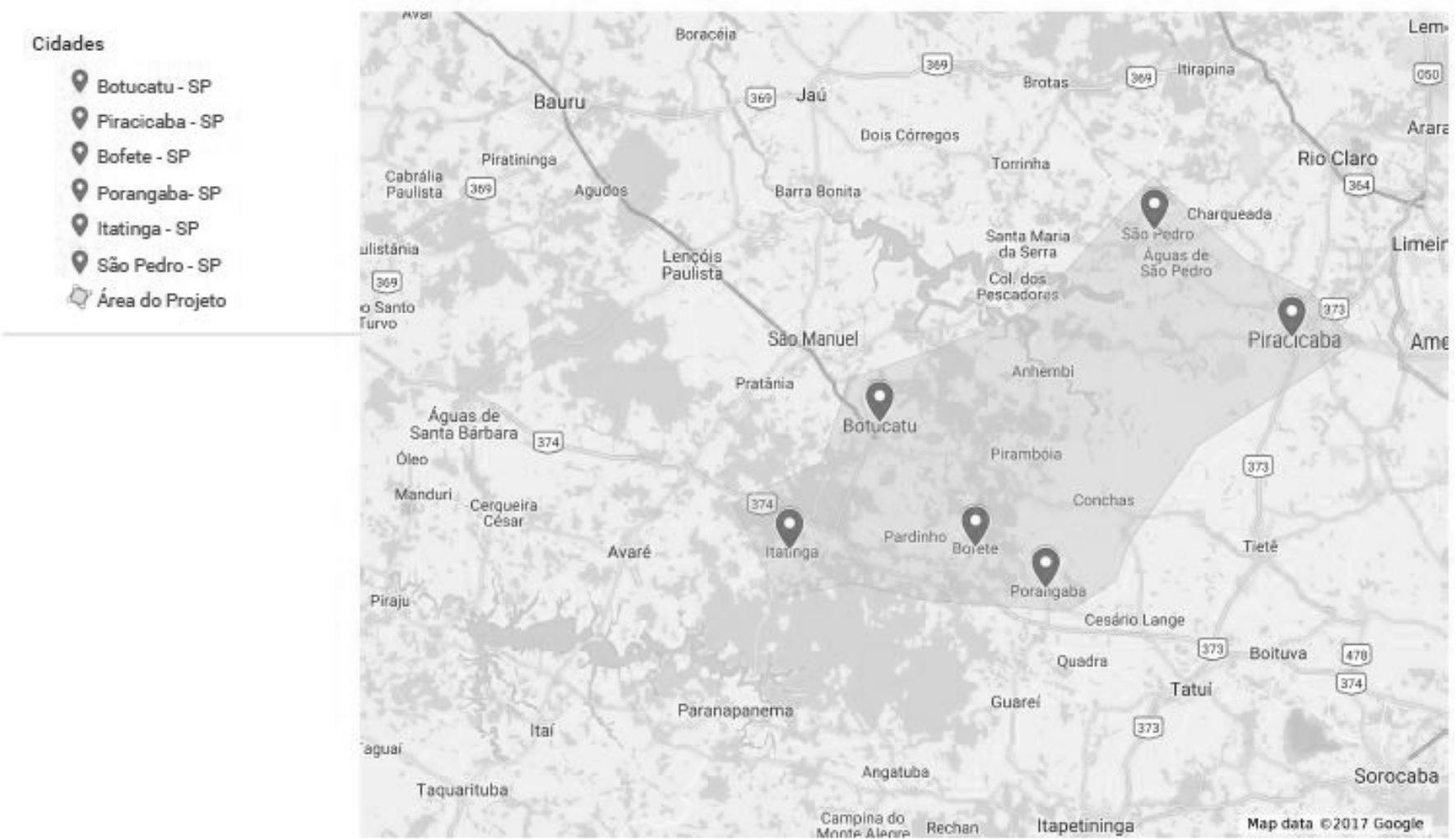

Fig.1. Mapa com a distribuição geográfica das cidades envolvidas no estudo, localizadas no interior do estado de São Paulo. 
O estudo foi dividido em duas etapas: a primeira de triagem e a segunda com coleta individual. Dessa forma, foi possível verificar a prevalência dos rebanhos na região em estudo e, posteriormente, a prevalência dentro dos rebanhos positivos, verificando quais e quantos animais estavam infectados.

$\mathrm{Na}$ fase de triagem, foram utilizadas as 67 propriedades localizadas no interior do estado de São Paulo, com a realização de três coletas em cada uma delas, e intervalo de $15 \pm 7$ dias entre as coletas, para aumentar a sensibilidade do estudo. As amostras de leite foram colhidas diretamente dos tanques de expansão após homogeneização, com auxílio de concha de alumínio previamente esterilizada, acondicionadas em frascos coletores universais estéreis e transportadas sob refrigeração $\left(4-8^{\circ} \mathrm{C}\right)$, em caixas isotérmicas contendo gelo reciclável. No caso de propriedades que não possuíam tanques de refrigeração e, portanto, faziam uso de tanques comunitários, a coleta foi realizada diretamente do recipiente no qual o leite chegava, latão ou tambor, após homogeneização. Em todos os casos, foram coletadas amostras de leite de aproximadamente $25 \mathrm{~mL}$, destinadas às análises laboratoriais.

Para coleta individual, as propriedades positivas para Mycoplasma bovis, foram visitadas para obtenção de amostras de leite dos animais. Para tanto realizou-se a prova de Tamis e CMT em todos os tetos de todas as vacas em lactação para o diagnóstico de mastite. Amostras de leite de quartos com mastite clínica ou subclínica (reação a partir de uma cruz (+) no exame de CMT) foram coletadas para análise laboratorial, após a lavagem com água e desinfecção do óstio do teto com solução de álcool iodado a 0,25\%. Foram colhidas amostras de $5 \mathrm{~mL}$ de leite em duplicata, em frascos estéreis, para a realização de exame microbiológico bem como para o estudo molecular da presença de Mycoplasma bovis. As amostras foram transportadas para o laboratório sob temperatura de refrigeração, em caixa de material isotérmico contendo gelo reciclável.

Exames laboratoriais. As amostras de leite obtidas na fase de triagem foram submetidas a contagem de células somáticas e a detecção molecular de Mycoplasma sp. e Mycoplasma bovis.

Amostras de leite dos quartos positivos ao CMT ou de casos de mastite clínica, na coleta individual, foram submetidas a provas moleculares para detecção de Mycoplasma sp.e Mycoplasma bovis, cultivando-se ainda em meio de caldo SP4 para tentativa de isolamento de Mycoplasma bovis.

Detecção molecular. A extração do DNA foi realizada a partir de $200 \mu \mathrm{L}$ de leite, utilizando-se o kit comercial blood genomicPrep Mini Spin Kit (GE Healthcare), com adaptações padronizadas previamente, tais como a retirada da gordura do leite, e adição de lisozima e tampão de lisozima. A quantificação foi realizada pela corrida eletroforética em gel de agarose 1,5\% com marcadores low mass DNA (invitrogen).

Para a detecção molecular de Mollicutes e Mycoplasma bovis, foram utilizados iniciadores que amplificam regiões espécie-específicas do DNA codificadoras das regiões 16S e 23S rRNA, baseado nas sequências do banco de dados do GenBank. As reações de PCR foram realizadas com um volume total de $25 \mu \mathrm{L}$ contendo tampão de reação $10 \mathrm{mM}$ Tris $\mathrm{HCl}$ pH 8,0, $50 \mathrm{mM} \mathrm{KCl}, 1,5 \mathrm{mM} \mathrm{MgCl} 2,0,2 \mathrm{mM}$ de dNTP, $10 \rho \mathrm{M}$ de cada primer, 0,5 unidades de Taq Platinium (Invitrogen) e 10ng de DNA. A incubação foi realizada em termociclador Mastercycler gradient (Eppendorf).

A amplificação do DNA de Mollicutes foi realizada utilizando os primers MGSO (5’ TGC ACC ATC TGT CAC TCT GTT AAC CTC 3') e GPO-3 (5' GGG AGC AAA CAG GAT TAG ATA CCC 3'), comum produto de 270 pares de base (Van Kuppeveld et al. 1992) e perfil de ciclos como segue: cinco minutos a $94^{\circ} \mathrm{C}$, trinta e cinco ciclos de $94^{\circ} \mathrm{C}$ por
30 segundos, $55^{\circ} \mathrm{C}$ por 30 segundos, $72^{\circ} \mathrm{C}$ por 30 segundos e uma extensão final a $72^{\circ} \mathrm{C}$ por $10 \mathrm{~min}$.

Uma vez positivas para a PCR com primers genéricos, foi realizada a amplificação do DNA de Mycoplasma bovis com o uso dos primers específicos MBOr (5' CCG TCA AGG TAG CAT CAT TTC CTA T 3') e MBOf (5'CCT TTT AGA TTG GGA TAG CGG ATG 3'), com produto de 360 pares de bases (González et al. 1995) e o seguinte perfil de ciclo: um ciclo de $94^{\circ} \mathrm{C}$ por três minutos, trinta e cinco ciclos de $94^{\circ} \mathrm{C}$ por um minuto, $60^{\circ} \mathrm{C}$ por um minuto, $72^{\circ} \mathrm{C}$ por um minuto e uma etapa final de $72^{\circ} \mathrm{C}$ por três minutos.

A visualização do material amplificado foi avaliada pela corrida eletroforética em gel de agarose a 1,5\% adicionado de $0,025 \mu \mathrm{L} / \mathrm{mL}$ de brometo de etídeo. A corrida eletroforética foi realizada em cuba horizontal contendo TBE 1X (89 nM Tris-HCl, 89 mM ácido bórico e $20 \mathrm{mM}$ EDTA) e a voltagem empregada foi de 65V. Após o término da corrida, o gel foi visualizado em transluminador de luz UV (Maniatis et al. 1982) e a imagem capturada pelo sistema de documentação digital.

Exame microbiológico para isolamento de Mycoplasma spp. Para isolamento de Mycoplasma spp. foi realizado previamente a padronização de técnicas de cultivo a partir de amostras de leite bovino, provenientes dos tanques, na fase de triagem e dos quartos positivos na fase individual, estabelecendo-se o seguinte protocolo: Cultivo de $0,2 \mathrm{~mL}$ de cada amostra diretamente em meio SP4 (triptona, peptona e caldo base) líquido, suplementado com soro fetal bovino, meio 199, extrato de levedura, glicose, arginina, bacto TC yeastolate, vermelho fenol, acetato de thalium e penicilina, polimixina B (Tully 1995). Simultaneamente, foram cultivados $0,05 \mathrm{~mL}$ de cada amostra em placas de Petri (Pleion A-24) em meio sólido SP4 (triptona, peptona, caldo base e ágar noble) suplementado, conforme descrito anteriormente. A incubação foi procedida em ambiente de microaerofilia, em estufa de CO2, com posterior observação do isolamento microbiano a cada 3 dias por até 15 dias de incubação.

A avaliação do isolamento de micoplasmas foi realizada pela visualização em microscópio invertido e estereomicroscópio pelo exame das placas de cultivo, de colônias apresentando aspecto característico de "ovo-frito" e com formação de filmes e manchas conforme descrito por Pretto et al. (2001).

Para confirmação do gênero Mycoplasma, as amostras inoculadas em caldo SP4 foram submetidas a três filtrações sucessivas em membrana $0,22 \mu \mathrm{M}$ e incubação a $37^{\circ} \mathrm{C}$ em ambiente de microaerofilia, descartando desta maneira possíveis casos de contaminação.

\section{RESULTADOS E DISCUSSÃO}

Na fase de triagem das 67 propriedades, 11 foram positivas na PCR para classe Mollicutes, com uma prevalência de $16,4 \%$. Dessas amostras apenas uma foi positiva na PCR para Mycoplasma bovis com uma prevalência de 1,4\% do agente na região em estudo. Prevalências igualmente baixas foram encontradas em estudos de amostras de leite de tanques em outros países como 5,4\% na Grécia (Filioussis et al. 2007), 1 a $8 \%$ nos Estados Unidos (Fox et al. 2003), 1,8\% na Thailândia (Kampa et al. 2009) e 1,5\% na Bélgica (Passchyn et al. 2012) não tendo sido isolado em estudo realizado na Nova Zelândia (McDonald et al. 2009).

As demais amostras positivas para Mollicutes podem ser positivas para outras espécies de micoplasmas causadoras de mastites, como Mycoplasma alkalenses, M. arginini, M. bovigenitalium, M. bovirhinis, M. californicum, M. canadense, M. dispar, assim como patógenos de outro gênero já relatados em casos de infecção da glândula mamária como 
Acholeaplasma spp. (principalmente A. laidlawii e A. axanthum) (González \& Wilson 2003).

Importante salientar que a amostra positiva para M. bovis foi obtida em apenas uma, das três coletas realizadas na mesma propriedade, ou seja, no mesmo local apenas em um dos momentos detectou-se o patógeno. Tal fato se deve a excreção intermitente do agente ou pela sua eliminação em quantidades muito baixas, dificultando a sua detecção nos exames realizados.

Estudo similar realizado com amostras de leite de tanques, em Quebec (Francoz et al. 2012) revelou da mesma forma, que os mesmos tanques com a presença do agente em um mês, não mais o apresentavam no mês subsequente. Tal fato pode ser justificado pela baixa concentração do agente excretada no leite de tetos infectados, podendo ser menor que 10UFC/mL, valor mínimo no limiar de detecção da técnica de PCR e muito menor que o limiar do cultivo, de $100 \mathrm{UFC} / \mathrm{mL}$ (Biddle et al. 2003).

Todas as amostras foram negativas no cultivo microbiológico em meio seletivo para mycoplasma, o que demonstra baixa sensibilidade da técnica. Sabe-se das dificuldades do isolamento desse patógeno considerando-se as exigências quanto aos meios de cultivo e entre outras características, bem como a carga microbiana presente na amostra, além do aspecto de crescimento fastidioso nos meios de cultivo (Junqueira \& Langoni 2016).

No caso de coleta individual, foram examinados 152 animais em lactação, totalizando 608 tetos (592 funcionais e 16 perdidos), provenientes da propriedade positiva para $M$. bovis. Na prova de Tamis $6(1 \%)$ dos animais apresentavam mastite clínica. No CMT, 423 tetos $(71,4 \%)$ foram negativos, $10(1,7)$ reação de uma cruz (+), $58(9,8 \%)$ duas cruzes (++) e $95(16 \%)$ três cruzes (+++). Dos 152 animais, 101 (66,4\%) apresentaram mastite em pelo menos um dos quartos mamários.

Dentre as 169 amostras ( 6 de mastite clínica e 163 mastite subclínica), 13\% foram positivas na PCR para Mollicutes e nenhuma amplificou para $M$. bovis, tal fato pode ser explicado, pois durante o estudo, houve um período de tempo entre as coletas dos tanques das propriedades e a coleta individual de leite dos animais, da propriedade onde havia sido detectado M. bovis. Os animais infectados, que poderiam estar eliminando M. bovis, detectado no tanque, podem ter sido descartados, ou entrado no período seco.

Ressalta-se ainda a possibilidade da forma autolimitante da doença, como sugerido por Roy et al. (2008). É possível a ocorrência de cura espontânea nas mastites subclínicas, além da intermitência na eliminação de patógenos nas infecções intramamárias (Santos \& Fonseca 2007).

Quanto a tentativa de isolamento microbiano nos meios seletivos utilizados, os resultados também foram negativos tanto nos casos de mastite clínica como subclínica.

\section{CONCLUSÃO}

Pode-se concluir uma baixa prevalência de Mycoplasma bovis nas condições do presente estudo, mas enfatiza-se a necessidade de estudos com abrangência de outros estados brasileiros para determinação da sua prevalência em âmbito nacional.
Agradecimentos.- À Fundação de Amparo à Pesquisa do Estado de São Paulo (FAPESP, processo no 2011/16055-3).

\section{REFERÊNCIAS}

Biddle M.K., Fox L.K. \& Hancock D.D. 2003. Patterns of Mycoplasma shedding in the milk of dairy cows with intramammary Mycoplasma infection. J. Am. Vet. Med. Assoc. 223(8):1163-1166. http://dx.doi.org/10.2460/ javma.2003.223.1163. PMid:14584748.

Buzinhani M., Metiffogo E. \& Timenetsky J. 2007. Detecção de Mycoplasma spp. e Ureaplasma diversum em vacas com distúrbios reprodutivo. Arq. Bras. Med. Vet. Zootec. 59(6):1368-1375. http://dx.doi.org/10.1590/ S0102-09352007000600003.

Filioussis G., Christodoulopoulos G., Thatcher A., Petridou V. \& BourtziChatzopoulou E. 2007 Isolation of Mycoplasma bovis from bovine clinical mastitis cases in Northern Greece. Vet. J. 173(1):215-218. http://dx.doi. org/10.1016/j.tvjl.2005.08.001. PMid:16243548.

Fox L.K., Hancock D.D., Mickelson A. \& Britten A. 2003. Bulk tank milk analysis: factors associated with appearance of Mycoplasma sp. in milk. J. Vet. Med. B, Infect. Dis. Vet. Public Health 50(5):235-240. http://dx.doi. org/10.1046/j.1439-0450.2003.00668.x. PMid:12864899.

Fox L.K., Kirk J.H. \& Britten A. 2005. Mycoplasma mastitis: a review of transmission and control. J. Vet. Med. B, Infect. Dis. Vet. Public Health 52(4):153-160. http://dx.doi.org/10.1111/j.1439-0450.2005.00845.x. PMid:16000109.

Francoz D., Bergeron L., Nadeau M. \& Beauchamp G. 2012. Prevalence of contagious mastitis pathogens in bulk tank milk in Québec. Can. Vet. J. 53(10):1071-1078. PMid:23543925.

González R.N. \& Wilson D.J. 2003. Mycoplasmal mastitis in dairy herds. Vet. Clin. N. Am., Food Anim. Pract. 19(1):199-221. http://dx.doi.org/10.1016/ S0749-0720(02)00076-2. PMid:12682943.

González Y.R.C., Bascuñana C.R., Bölske G., Mattsson J.G., Molina C.F. \& Johansson K.E. 1995. In vitro amplification of the 16S rRNA genes from Mycoplasma bovis and Mycoplasma agalactiae by PCR. Vet. Microbiol. 47(1/2):183190. http://dx.doi.org/10.1016/0378-1135(95)00058-I. PMid:8604550.

Junqueira N.B. \& Langoni H. 2016. Aspectos gerais sobre a mastite bovina causada por Mycoplasma spp. Vet. Zootec. 23(3):356-364.

Kampa J., Sukolapong V., Buttasrt A. \& Charoenchai A. 2009. Prevalence of Mycoplasma bovis and other contagious bovine mastitis pathogens in bulk tank milk of dairy cattle herds in Khon Kaen Province, Thailand. Wetchasan Sattawaphaet 39(3):275-280.

Langoni H. 2013. Qualidade do leite: utopia sem um programa sério de monitoramento da ocorrência de mastite bovina. Pesq. Vet. Bras. 33(5):620626. http://dx.doi.org/10.1590/S0100-736X2013000500012.

Maniatis T., Fritsch E.F. \& Sambrook J. 1982. Molecular Cloning: a laboratory manual. Cold Spring Harbor Laboratory, Cold Spring Harbor, New York. 545p.

McDonald W.L., Rawdon R.G., Fitzmaurice J., Bolotovski I., Voges H., Humphrey S., Fernando K., Canagasebey Y., Thornton R.N. \& McIntyre L. 2009. Survey of bulk tank milk in New Zealand for Mycoplasma bovis, using speciesspecific nested PCR and culture. N.Z. Vet. J. 57(1):44-49. http://dx.doi.or g/10.1080/00480169.2009.36867. PMid:19252542.

Mettifogo E. \& Tamaso E. 2013. Mastite por Mycoplasma bovis: Surtos em Minas Gerais levam ao Descarte de Animais Produtivos. Qualy Milk, São Sebastião do Paraíso. Disponível em <http://www.qualymilk.com/1/ post/2013/09/mastite-por-mycoplasma-bovissurtos-em-minas-geraislevam-ao-descarte-de-animais produtivos.html> Acesso em 16 dez. 2016.

Mettifogo E., Nascimento E.R., Müller E.E., Nascimento M.G.F. \& Freitas J.C. 1996. Mastite bovina por Mycoplasma bovis. Revta Bras. Med. Vet. 18:22-25. 
Nicholas R., Ayling R. \& McAuliffe L. 2008. Mycoplasma Diseases of Ruminants. Veterinary Laboratories Agency, CAB International, Wallingford, UK. 254p. http://dx.doi.org/10.1079/9780851990125.0000.

Nicholas R.A.J. \& Ayling R.D. 2003. Mycoplasma bovis: disease, diagnosis, and control. Res. Vet. Sci. 74(2):105-112. http://dx.doi.org/10.1016/S00345288(02)00155-8. PMid:12589733.

Owens W.E. \& Nipper W.A. 2008. Case study: development of a Mycoplasma mastitis control program in Louisiana. Professional Anim. Scientist 24:103106. Disponível em <http://findarticles.com/p/articles/mi_qa4035/ is_200802/ai_n24393806> Acesso em 16 dez. 2016.

Passchyn P., Piepers L., Meulemeester L., Boyen F., Haesebrouck F. \& Vliegher S. 2012. Between-herd prevalence of Mycoplasma bovis in bulk milk in Flanders, Belgium. Res. Vet. Sci. 92(2):219-220. http://dx.doi.org/10.1016/j. rvsc.2011.03.016. PMid:21481899.

Pretto L.G., Müller E.E., Freitas J.C., Mettifogo E., Buzinhani M., Yamaguti M. \& Salvador R. 2001. Mastite bovina por Mycoplasma bovis em rebanhos leiteiros. Pesq. Vet. Bras. 21(4):143-145. http://dx.doi.org/10.1590/ S0100-736X2001000400003.
Quinn P.J., Markey B.K., Carter M.E., Donnelly W.J. \& Leonard F.C. 2005. Microbiologia Veterinária e Doenças Infecciosas. Artmed, Porto Alegre. 512p.

Roy J.P., Francoz D. \& Labrecque 0. 2008. Mastitis in a 7-week-old calf caused by Mycoplasma bovigenitalium. Vet. J. 176(3):403-404. http://dx.doi. org/10.1016/j.tvjl.2007.04.006. PMid:17569564.

Santos M.V. \& Fonseca L.F.L. 2007. Microrganismos patogênicos transmitidos pelo leite, p.268-277. In: Ibid. (Eds), Estratégias para Controle de Mastite e Melhoria da Qualidade do Leite. Manole, Barueri.

Tully J.G. 1995. Culture médium formulation for primary isolation and maintenance of mollicutes, p.33-39. In: Razin S. \& Tully J.G. (Eds), Molecular and Diagnostic Procedures in Mycoplasmology. Vol.1. Academic Press, California. http://dx.doi.org/10.1016/B978-012583805-4/50005-4.

Van Kuppeveld F.J., Van der Logt J.T., Angulo A.F., Van Zoest M.J., Quint W.G., Niesters H.G., Galama J.M. \& Melchers W.J. 1992. Genus- and species-specific identification of mycoplasmas by 16S rRNA amplification. Appl. Environ. Microbiol. 58(8):2606-2615. PMid:1381174. 